ORGANISATIONAL JUSTICE, TRUST AND THE MANAGEMENT OF

\title{
CHANGE: AN EXPLORATION
}

Dr Mark NK Saunders", Reader in Research Methods, The Business School, Oxford Brookes University, Wheatley Campus, Wheatley, Oxford. OX33 1HX, UK. Email: mnksaunders@brookes.ac.uk

Dr Adrian Thornhill, Head of Department of Human Resource Management, Gloucestershire Business School, University of Gloucestershire, PO Box 220, The Park, Cheltenham, Gloucestershire, GL50 2QF, UK. Email: athornhill@glos.ac.uk

\section{BRIEF AUTOBIOGRAHICAL NOTES}

Dr Mark NK Saunders BA, MSc, PGCE, PhD, MCIPD is Reader in Research Methods and a member of the Management Development and Human Resource Management Department at Oxford Brookes University Business School. His research interests include human resource aspects of the management of change, downsizing and research methods.

Dr Adrian Thornhill BA, PhD, PGCE, FCIPD is Head of Department of Human Resource Management within the University of Gloucestershire Business School. His research interests include downsizing and the management of survivors, and change management.

\section{KEYWORDS:}

Trust, Organisational Justice, Change

\footnotetext{
* Author to whom all correspondence should be addressed
} 


\title{
ORGANISATIONAL JUSTICE, TRUST AND THE MANAGEMENT OF CHANGE: AN EXPLORATION
}

\begin{abstract}
This paper explores employees' trust as a reaction to the management of change using the constructs of organisational justice. Following a review of organisational justice theory in relation to trust and change, employees' reactions are considered using a case study of an UK public sector organisation. Drawing upon 28 in-depth interviews with employees, the nature of trust is explored. Little difference is found between trusting and mistrustful employees' perceptions of distributive justice. Supporting earlier findings regarding the relationship between procedural justice and trust, the research also reveals the distinct importance of fairness of treatment (interactional justice) in enabling trust.
\end{abstract}

\section{INTRODUCTION}

Organisational change is often perceived by individuals as threatening (Mabey and Salaman, 1995) requiring careful implementation to overcome mistrust associated with vulnerability and loss of security and well-being. Such feelings are commonly defined in terms of employees' confidence in, or reliance upon, someone or something (Guest, 1998). Consequently, perceptions about the processes through which change has been implemented, the outcomes and the treatment of those affected appear likely to influence whether employees feel trusting or mistrustful. 
Organisational justice theory offers a framework through which to explore and understand employees' feelings of trust or mistrust more fully. Organisational justice integrates the outcomes of organisational change with the methods used to achieve it, and perceptions about the treatment of those affected. In this paper, we commence by conceptualising the relationship between trust and organisational justice within the context of change. Using a case study drawn from a United Kingdom (UK) public sector organisation, we then examine employees' self categorized feelings of trust and mistrust within this conceptualisation. We conclude with a discussion about the implications of this for enabling trust during organisational change and for organisational justice theory, and reflect briefly on the limitations of this study and directions for future research.

\section{ORGANISATIONAL JUSTICE, TRUST AND CHANGE: AN OVERVIEW}

Organisational justice theory (Greenberg, 1987) focuses on perceptions of fairness in organisations, by categorising employees' views and feelings about their treatment and that of others within an organisation. Three types of organisational justice theory have been identified in the literature (Greenberg, 1987; Folger and Cropanzano, 1998). Perceptions about the outcomes of decisions taken form the basis of distributive justice (Homans, 1961; Leventhal, 1976). Perceptions about the processes used to arrive at, and to implement, these decisions form the basis of two further types of justice that are often treated as one in the literature; these are procedural justice and interactional justice (for example Cropanzano and Greenberg, 1997). Procedural justice focuses on employee perceptions of the fairness of procedures used to make decisions (Thibaut and Walker, 1975). This has been distinguished from interactional 
justice which focuses on employees' perceptions about the fairness of the interpersonal treatment received during implementation (Bies and Moag, 1986).

Development of trust theory has, to date, been more disparate focusing on a range of levels of analysis from the interpersonal to the inter-organisational (e.g. Rousseau et al., 1998). Although this has resulted in a variety of definitions of trust, these exhibit a number of common elements including notions of 'favourable expectations' and a 'willingness to become vulnerable'. Möllering (2001) has sought to use and develop these elements, arguing that trust develops from favourable expectations that are based upon interpretations of the reality to which trust relates, enabled by a suspension of disbelief and a corresponding leap of faith. This suggests that the process through which trust is developed is informed by socially constructed interpretations of reality that include a willingness to make judgements about as yet unresolved situations and a leap of faith about unknown ones. Trust, according to this approach, is based upon the acceptance of interpretations that includes awareness that information is imperfect. Accordingly, a "mental leap of trust" is made, or required, from interpretation to expectation for trust to be developed (Möllering 2001: 412).

Herriot et al (1998)'s four manifestations of trust offer a means of relating Möllering's (2001) process based definition to organisational change. Their first manifestation emphasises confidence that expectations of the outcomes of change will be favourable, namely that obligations will be fulfilled. The second relates to a belief about not being deceived. For example, that managers will not be selective with the truth or actively deceive those they manage. In contrast, the third emphasises a willingness to become vulnerable, focusing on the trust placed in the abilities of those 
managing the change process to undertake this role. Finally, the fourth deals with trust originating from a belief that people are benevolent, will not harm employees (again emphasising vulnerability) and may even care for their welfare during the change process (implying an additional leap of faith). We consider each of the types of organisational justice in turn alongside the likely implications for these manifestations of trust.

\section{Distributive justice and trust}

Within a change context, distributive justice is concerned with perceptions of fairness arising from organisational allocations and outcomes. Pillai et al (2001) argue that when distributions of organisational outcomes are considered fair, higher levels of trust are likely to ensue. In a similar way, Herriot et al.'s (1998) first manifestation of trust is based on the fulfilment of perceived obligations. According to these formulations the experience of fulfilled obligations is directly related to the generation of trust.

Adams (1965) proposed that feelings of inequity would arise where the ratio of a person's outcomes in relation to their inputs from an exchange were perceived as disproportionate, as the result of a comparison with others. Perceptions of unfairness may lead to positive inequity, where a person perceives that another had a greater claim to a particular allocation leading to a feeling of guilt. In this way an outcome may be favourable but it may not facilitate fairness or trust due to perceptions about lack of integrity in relation to the process (e.g. Bews and Uys, 2002). Alternatively, perceptions of unfairness may lead to negative inequity, where a person feels that they 
had a greater claim to an outcome compared to the person receiving it, leading to feelings of anger and possibly mistrust.

Perceptions of distributive justice are based largely on comparisons with others (Adams, 1965; Cropanzano and Greenberg, 1997; Greenberg, 1987). Similarly, perceptions about obligations and trust are likely to be related not just to an absolute measure, about whether obligations have been fulfilled, but also to one or more relative, social comparisons. These are termed referent comparisons or standards. Feelings of trust are therefore likely to be affected by the relative treatment of others and by more generalised opportunities available within a person's occupational group, organisation or perhaps even another organisational context.

\section{Procedural justice and trust}

Assessments of trust depend not only on perceptions about fairness of allocations and outcomes but also about the procedures used to arrive at such decisions. Procedural justice is concerned with perceptions of fairness about such procedures and processes. Folger and Konovsky (1989) for example, found that employees who felt that their supervisor had conducted appraisals in a fair manner tended to rate their trust more positively. More recently, Brockner and Siegel (1996) suggested that positive individual views of processes and procedural justice were likely to be linked to higher levels of trust in the organisation and in supervisors. Since the conceptual development of procedural justice in the mid-1970s (e.g. Thibaut and Walker, 1975; Leventhal, 1976), the importance of this concept for many aspects of human resource management has been recognised (Folger and Cropanzano, 1998). In particular, 
genuinely fair procedures and processes have been found to moderate the impact of negative reactions such as mistrust that arise from decisions leading to undesirable employee outcomes (Brockner and Siegel, 1996).

Research to understand the dynamics of procedural justice has focused on the related concepts of voice (Folger, 1977) and process control (Thibaut and Walker, 1975). Voice, or participation, allows those affected to exercise some degree of process control, or personal influence, in relation to the process of reaching a decision (Thibaut and Walker, 1975; Greenberg and Folger, 1983). This ability has been linked to a number of positive attitudinal and behavioural reactions, including improved trust in management (Mishra, 1996; Tyler and Lind, 1992).

Leventhal's $(1976 ; 1980)$ work details other facets that have been found to promote procedural justice. These relate to the consistent application of organisational procedures; the avoidance of self interest in the application of procedures; accuracy in their use based on reliable information; scope to evaluate the application of procedures and alter outcomes where necessary; allowing for the representation of differing interests, and the adoption of ethical standards through their use. Many of these facets that promote procedural justice are linked to Herriot et al.'s (1998) second manifestation of trust, namely employees' belief they are not being deceived. In particular, they emphasise the importance of integrity in ensuring the fair and consistent application of moral and ethical procedures to generate equity and trust (Bews and Uys, 2002). It therefore seems that, as suggested by Brockner and Siegel (1996), fair procedures will engender trust in the change process and those implementing the change. In contrast, a lack of procedural fairness is likely to elicit 
lower levels of trust. Such perceptions may be seen to have a greater impact than those related to distributive justice because, whereas outcomes are viewed as happening only once, procedures are considered to have a more enduring quality (Pillai et al., 2001; Tyler, 1989); although in practice the two are likely to be closely related.

\section{Interactional justice and trust}

Perceptions about procedural justice related to change may be differentiated from justice considerations arising from their implementation. Initially, perceptions about procedural justice will arise in relation to the scope for those who are likely to be affected by a decision to be able to exercise voice and to engage in some level of process control. Perceptions about whether the decision-making procedure is just or unjust are likely to inform their level of trust. However, the degree of trust this engenders may be altered by the perceived fairness of the interpersonal treatment received. This has been identified as being composed of two principal elements relating to the explanations and justification for decisions made and the level of sensitivity of treatment and benevolence towards those affected during their implementation of change (Bies and Moag, 1986; Mayer et al., 1995).

Justification of organisational decisions through effective explanations has been found to produce an effect similar to that of process control (Daly and Geyer, 1994). This may be explained through the finding that employees are more likely to accept decisions, even unfavourable ones, when given an adequate and genuine reason for it (Brockner and Wiesenfeld, 1993; Daly and Geyer, 1994). These findings point to the 
central role that effective communication may play in engendering trust in a change context (e.g. Folger and Cropanzano, 1998), and possibly to enable the suspension of disbelief and any corresponding leap of faith.

Similarly, the way in which individuals are treated during a period of change has been found to affect their perceptions about the fairness of the process (Folger and Cropanzano, 1998). This suggests a clear role for line managers in relation to the development of their subordinates' perceptions about fairness and the generation of trust through acts of benevolence (Mayer et al., 1995, Mishra, 1996; Tyler and Lind, 1992), Herriot et al.'s (1998) fourth manifestation of trust. The nature of the way in which people are treated is therefore likely to have a significant impact on the perceptions that they form about fairness, not only about the process of implementation in general but also about the moral obligation to treat everyone fairly that underpins this process and thus their levels of trust.

Interactional justice was therefore introduced as a third and discrete construct of organisational justice. Because it has been evaluated as producing the same type of perceptual outcomes as procedural justice, it has been approached more recently as a facet of procedural justice rather than as a separate factor of organisational justice (Cropanzano and Greenberg, 1997). However, the conflation of these two types of organisational justice on the basis of similar perceptual outcomes obscures the possibility of differential impacts on trust and, in particular, differing implications for enabling Möllering's (2001) leap of faith. We return to this in our exploration of the data. 


\section{DATA COLLECTION}

Data were collected from a case study public sector organisation, which we refer to as "Newcounty". Newcounty had come into existence on $1^{\text {st }}$ April 1998, as part of local government reorganisation in England and Wales. This county council was formed as part of the division of the previous county and district councils into two separate groupings, consisting of a unitary authority and a new county council with district councils. Within this structure, Newcounty was responsible for provision of education, caring services, police, traffic, road building and maintenance, libraries and strategic planning. The creation of Newcounty inevitably involved considerable change and uncertainty for those employed by the old county council. The change in geographical area served and need for new organisational structures created uncertainty regarding continuation of employment, although there had been an undertaking that there would be no compulsory redundancies.

At Newcounty's request, this research commenced approximately one year after the county council had been created. This meant employees would have been able to reflect upon the changes they had experienced and there would, in Newcounty's terms, be "sufficient time for the new county council to settle down". Data collection incorporated two integrated methods utilising structured and unstructured approaches: a card sort followed by in-depth interviews. These data were obtained from a random sample of 28 employees. Employees were stratified according to level within the organisation's hierarchy including administrative and technician employees (10), professionals and middle managers (15) and senior managers (3); the sample being 
drawn from across the five directorates, namely Corporate (8), Educational excluding those based in schools (3), Environmental (7), Financial (3) and Social Services (7).

The card sort involved consideration of 21 negative emotions and 19 positive emotions that might be experienced in relation to organisational change. These were derived from the literatures relating to psychology and stress (Brockner, 1988; Brockner et al., 1987, 1992; Brockner and Greenberg, 1990; Lazarus and Folkman, 1984). The items 'trusting' and 'mistrustful', although not appearing generally in such lists, were also included within these emotions thereby allowing relationships with perceptions of trust to be explored in subsequent analyses. Each employee was asked to "think about themselves in relation to the changes associated with the creation of [Newcounty]" and to sort the 40 cards into "do not feel" and "feel to some extent". Subsequently each was asked to select those cards which she or he "felt strongly" and from these to identify three about which they felt most strongly (table 1). This was followed by an unstructured interview, of approximately one hour's duration, focusing initially on these three most strongly felt emotions. The principal aims of each interview were to discover the employee's interpretation of the cards selected and to explore the reasons for these emotions in the context of the creation of Newcounty. As part of this process, interviewees were encouraged to describe and discuss their emotions in the context of their own perceptions of the changes. Notes from these interviews were subsequently transcribed and analysed using a process of categorisation to search for key themes and patterns (Dey, 1993). This allowed employees' perceptions of trust, which had been self categorised as 'trusting', 'mistrustful' or neutral (selecting neither), to be explored in relation to the facets of 
organisational justice from a grounded and subjective perspective (Cropanzano and Greenberg, 1997).

\section{TRUST AND EMPLOYEES' REACTIONS}

The card sort provided an overview of employees' reactions to the changes associated with the creation of Newcounty. 54\% of respondents felt 'trusting' at least to some extent, compared with $18 \%$ who felt 'mistrustful', with the remaining $28 \%$ selecting neither. Consideration of employees three most strongly felt emotions indicated that, overall, 'trusting' respondents were more likely to feel positive towards the changes. $80 \%$ of emotions selected by those feeling 'trusting' represented positive feelings in relation to the changes (table 1), the emotions of 'positive', 'determined' and 'involved' being all selected by at least a quarter of all respondents. In contrast, only $21 \%$ of emotions selected by those who felt 'mistrustful' were positive. For these employees, the most common negative emotions were 'frustrated' and 'under pressure', both selected by two respondents.

\section{Ideal place for table 1}

Analysis of the three most strongly felt emotions suggested three groupings. The first of these represents those who could be considered as feeling positive in relation to the changes who chose positive emotions as those about which they felt most strongly. The eleven respondents in this group selected emotions such as 'positive', 'enthusiastic', 'optimistic', 'confident', 'keen', 'comfortable', 'hopeful', 'in control' and 'relieved' (table 1). Nine of these positive respondents had also selected 
'trusting' as felt at least "to some extent" in the previous stages of the card sort process. They were drawn from all directorates and at a range of levels within the organisational hierarchy.

The second group chose negative emotions as those about which they felt most strongly such as 'frustrated', 'demoralised', 'insecure' and 'stressed'. This group represents employees who could be considered as feeling negative in relation to the changes (table 1). Three of these six negative respondents had also selected 'mistrustful' as felt at least "to some extent" in the previous stages of the card sort process. Although predominantly from the Educational and Environmental Services directorates, these respondents again represented different levels within the organisational hierarchy.

The third grouping represents people with mixed feelings, selecting either two positive emotions such as 'involved' and 'determined' alongside a negative emotion, or two negative emotions such as 'under pressure' and 'powerless' alongside a positive emotion. Although these employees represented all five directorates, the majority was males in professional or managerial positions. Within this group, those who were 'trusting' tended to discuss the negative emotions they felt within the context of a positively oriented set of perceptions about the organisational change that they had experienced. For example, two 'trusting' respondents (a male and a female) who selected predominantly positive emotions justified their selection of the negative emotion 'under pressure' because they had been promoted and there was "pressure to perform and do a good job". Respondents who felt 'mistrustful' or neutral appeared more likely to have selected two negative emotions, although the pattern was less 
clear. This suggested that there was likely to be a far clearer relationship between employees' who had made a mental leap of trust and feeling generally positive than between those who felt 'mistrustful' or neutral and feeling generally negative towards the change.

It is to the reasons for these three types of trust response that we now turn. Using the theories of organisational justice outlined earlier, we compare and contrast the reasons offered by the fifteen respondents who felt 'trusting' with the five who felt 'mistrustful' and the eight who felt neutral in relation to the changes. Within this comparison, we commence by examining perceptions about distributive justice prior to looking at those about procedural and interactional justice.

\section{UNDERSTANDING TRUST AS A REACTION - PERCEPTIONS OF JUSTICE}

\section{Distributive justice}

Two thirds of respondents who felt 'trusting' linked this to the distributive outcomes of the changes. This aspect of justice was discussed at two discrete levels, firstly as the outcome for Newcounty within the wider context of local government reorganisation in England and Wales and, secondly, with regard to the outcome of the process for individual employees. The majority of 'trusting' respondents stated that the creation of Newcounty was a fair outcome in relation to the wider process of reorganising local government. However, whilst believing the overall outcome was fair there was also an awareness that other resource outcomes for Newcounty were not 
necessarily fair. This was typified by a 'trusting' male professional employee who, when discussing Newcounty's new emphasis on public service, qualified it with the phrase "in spite of being strapped for cash", providing an illustration of the use of contextual referent standards. All those who were 'trusting' commented favourably about their personal outcomes, referring often to a feeling of involvement. A minority also highlighted improvements in training and development opportunities in comparison with the old county council.

Respondents who felt 'mistrustful' or neutral in relation to the changes, focused only on their personal outcomes. For these employees, discussion highlighted the unfavourable nature of their outcomes compared to other employees rather than any feeling of inherent unfairness or that obligations had not been fulfilled. For two male respondents, both in technician posts, the receipt of statutory protection of jobs and salaries for three years was considered a fair but unfavourable outcome compared to colleagues. Employees who felt 'mistrustful' or neutral therefore appeared to be evaluating their personal outcomes against immediate colleagues' experiences, whereas those who felt 'trusting' also used their previous employment experiences. These differences were particularly apparent during discussion of involvement in the organisation's work and perceptions of employment benefits.

\section{Procedural justice}

Employees at all levels in Newcounty had inevitably been involved in the change process, if only because they had applied for and been appointed to posts within the organisation. Those who felt 'trusting' commented that the procedures used to recruit 
staff to Newcounty were drawn out, especially for those lower down the organisational hierarchy. A senior (male) manager commented: "there were false promises e.g. the appointments process took longer." However, despite this, those who felt 'trusting' did not view the actual process as being unfair, rather that it had ended up being compressed. One female clerical worker illustrated this, when talking about her feeling of 'relief', commenting: "The process towards the end was much too short. The majority was desperate to see jobs first on the email, get applications in and have the first interview. They felt that if you didn't get the details within the first half hour it was too late, yet provided you hit the deadline, it didn't matter." The drawn out nature of the recruitment process was also highlighted by those who felt 'mistrustful'; a typical comment which inferred deception being "For all those months progress could have been made, they must have known what was needed." Despite this, all but two of these respondents commented that the overall procedures were fair.

Differences were apparent between 'trusting' and other respondents in the extent to which they felt they had been allowed voice in the process. In general, both female and male respondents at all levels of the hierarchy who felt 'trusting' considered they had contributed to the process of creating the new organisation. Often when justifying the selection of a positive emotion, they highlighted opportunities they had to express their views and emphasised that these views had been taken into account. However, this perception of effective voice was not supported by the examples given by those in more junior posts. Rather it appeared that, although such employees were being given the opportunity to be involved and voice opinions, their impact on the process was less clear. This was typified by one female supervisor's comment: "We were even 
involved in the meeting about the corporate badge. This wouldn't have happened under the old [county council name]."

These perceptions about voice in the change process contrasted markedly with some respondents who felt 'mistrustful' or neutral. These people argued that the procedures had been reactive rather than proactive or that they felt powerless throughout the change process. This was typified by a male technician who likened the process to "tossing a coin" and by a manager who when discussing her feeling of 'powerlessness' commented "I appreciate that my department is only a small cog perhaps it was unrealistic of me to expect more involvement." Such employees, whilst they had begrudgingly accepted the outcomes, did not feel involved in the process or that it had been fair.

\section{Interactional justice}

Interviews with all respondents suggested a separate and distinct aspect to their perceptions of justice based upon the nature of the interpersonal treatment they had received throughout the change process. Although respondents were not necessarily involved in managing the process of change themselves, their justifications for choosing their three most strongly felt emotions (both negative and positive) emphasised the importance of social aspects of their treatment, in particular their support and respect by senior managers. As suggested by the literature (e.g. Cropanzano and Greenberg, 1997), these social or interactional aspects fall into two distinct groupings: the nature and adequacy of the information available and the extent to which people were treated with dignity and respect. In general those who felt 
'trusting' felt these had been fair, whilst those who were 'mistrustful' or neutral tended to feel the converse.

Comments by those who felt 'trusting' emphasised the maintenance of communication throughout the change process, drawing comparisons with the inadequacy of communication in the old organisation. The weekly newsletter was highlighted by over half of these respondents as an important source for gaining information and explanations about what was happening during the change process. A similar view was expressed about face-to-face communication from senior managers; a typical comment from a positive middle manager recipient being "I like the way I was involved by members and officers in reorganisation -this was new. They explained their views and the way things were going. I like the way [Newcounty] has taken this forward to be a listening council."

In contrast, some of those who were neutral emphasised the inadequacy of the explanations they received. One manager commented "we felt there was a lack of information about the process, e.g. we can't say for sure what's going to happen, I found it difficult to motivate my staff because of this indecision" whilst a technician commented there "...were just rumours and handouts [newsletters] for ten months." Those who felt 'mistrustful' appeared more cynical about their treatment by senior managers and, as a consequence, less likely to believe that the informational or social sensitivity aspects of their interactions were just. Their cynicism in relation to social sensitivity is illustrated by a comment about support received by one employee from her manager. "I saw my line manager and said I'd had enough... I don't want to come here. She said I needed stress counselling. I saw the stress consultant who said 
'you're not stressed, your pissed off, get out' [of the job you're doing]". Comments in relation to communication support this, a more junior manager saying: "Regular seminars were a good idea... I hope it was a genuine informing rather than just 'isn't everything wonderful' - there's a lot of ego in it." In both these cases, discussion suggested that, on the basis of these interactions, employees were unwilling to suspend their awareness of the unknown and unresolved or to make the mental leap of trust.

Respondents who felt 'trusting' appeared to derive a feeling of being valued and respected from their social interactions with senior management. A male junior manager stated "The important thing for me is that the Chair of the Committee was very up-front and supportive" whilst a female supervisor partially justified her selection of positive emotions stating: "I feel valued. Management appears more caring -actions and words suggest this. They know staff names -before they would ignore staff..., they were incredibly rude. They value you as a person and have focused back on people being important." Interviews implied that the majority of 'trusting' respondents perceived their interaction with senior management as two-way, despite their reported reality of a predominantly one-way interaction. This seems likely to be due to the quality of the interpersonal treatment received.

Disparities were apparent between 'trusting' and other respondents in their comments about their treatment by line managers. Those who felt 'trusting' commented that line managers had treated them justly with dignity and respect. The majority stated their own line manager had been very positive and supportive through listening to their views. Many believed the motives for this were altruistic, with the majority 
commenting upon the apparent "genuineness" of managers wanting to listen to and help their staff. Whilst this was also apparent in the comments of some neutral respondents, they were more ambivalent suggesting they had not made the leap to trust. One male senior manager commented: "some of the actions are a bit twee and staff see this but they still say at least he made the effort". Respondents who felt 'mistrustful' suggested there was little social sensitivity or thought for their welfare from their line managers, typical responses being: "she just said 'get on with it"" and "he didn't want to know". For these 'mistrustful' employees, disrespectful treatment was also perceived in the physical surroundings in which they found themselves working. A somewhat extreme example of this was given by a technician who commented "When I got to my new office I found no phone, no desk or lockable drawers and yet everyone else was sorted out."

Comments highlighted that interactions, although face-to-face, differed depending on the hierarchical distance between employees. Interactions between junior and more senior managers relating to the work of the organisation were predominantly one-way, often consisting of presentations to large groups, or the offering of greetings. In contrast, interactions with the immediate manager were more likely to be two-way. Where both of these types of interaction were interpreted as being two-way employees appeared to be trusting. However, where interactions with line managers were interpreted as one-way, employees appeared less likely to be trusting. Where interactions between employees and managers lacked sensitivity for the more junior employee or were considered unjust, employees appeared mistrustful. These 'mistrustful' employees were usually also cynical about the nature and intent of interactions with senior management. 


\section{DISCUSSION}

Our analysis points to an important finding about the relationship between perceptions of fairness and feelings of trust for the nature of distributive justice. Employees who felt that the change outcomes were fair for both the organisation and themselves were trusting, whereas those whose discussion focused only on the fairness of their personal outcomes tended to feel mistrustful or neutral. This finding in relation to those who were 'trusting' implies a conceptualisation of distributive justice at more than just an individual level. Whereas the literature recognises the link between organisational decisions and perceptions of fairness related to individual allocations and outcomes, our findings point to perceptions that were not only focused on individual allocations but also broader organisational outcomes. This suggests that those who showed concern not only about allocations for themselves but also outcomes for the organisation were more likely to be 'trusting', perhaps because they felt a higher level of commitment to it and a greater degree of social identity as an organisational member (Haslam, 2001).

Although the reality of procedural involvement in Newcounty suggests that only those in more senior positions exercised real process control, the majority of respondents felt they had been offered the scope to be involved as part of these changes. This feeling led to a general perception of procedural fairness that appears at an aggregate level to have had some influence on feelings of trust. Whilst the relationship between the scope for involvement and the resulting perception of procedural fairness fulfils the prediction suggested by extant literature, this raises an issue about why so many 
employees felt that they had been able to influence the process whereas the reality often suggested otherwise.

Consideration of interactional justice highlighted a range of responses with associated respondents' feelings of trust, neutrality or mistrust. When interactions with senior management are considered, those who perceived interactions as two-way were most likely to feel 'trusting' whereas those who considered they were one-way were least likely to do so. In discussion, those who felt they had been listened to and treated with dignity and respect were more likely to feel trusting. In contrast, those who were cynical about their treatment were likely to feel 'mistrustful'. The interaction between line managers and those they managed appears to be important in relation to the generation of perceptions of fairness about treatment. It suggests a linkage between the way in which employees interpret the change situation and some measure of willingness to become vulnerable and undertake the leap to trust suggested by Möllering (2001). This observation is supported by the majority of respondents who felt mistrustful being located in two of the five directorates, with discussion implying that people in these directorates may have received different interpersonal treatment.

It therefore appears that factors influencing perceptions of interactional justice were a key determinant of employees feeling 'trusting'. This suggests that interactional justice issues are considered separately by employees and therefore need to be considered separately rather than, as has been more common in recent years, as an aspect of procedural justice when considering the role of trust within a change process (Cropanzano and Greeberg, 1997). The results also highlight the importance of what can be termed reciprocated communication between line managers and employees as 
well as 'voice' in enabling some measure of disbelief to be suspended and feelings of trust engendered.

These findings have, we believe, significant implications for organisations, emphasising the pivotal role of line managers in promoting justice and enabling trust during change. In particular the findings emphasise the importance of good two-way communication and the demonstration of caring attitudes and roles by socially sensitive and skilled line managers. However, it should be remembered that these findings are based on employees from one public sector organisation responding to externally forced changes. Further research is required to establish if these outcomes may be replicated in different sectors and in relation to different change situations.

\section{REFERENCES}

Adams, J.S. (1965). Inequity in social exchange in Berkowitz L., (ed.) Advances in experimental social psychology Vol. 2, pp. 267-299 Academic Press, New York.

Bews, N. and Uys, T. (2002) The impact of organisational restructuring on perceptions of trustworthiness. South African Journal of Industrial Psychology Vol. 28, pp. 19-26.

Bies, R.J. and Moag, J., (1986). Interactional justice: Communication criteria of fairness in Lewicki, R., Sheppard, B. and Bazerman, M. (Eds.) Research on Negotiation in Organizations Vol. 1, JAI Press, Greenwich, CT. pp. 43-55

Brockner, J., (1988). The effects of work layoffs on survivors: research, theory and practice in Staw, B.M. and Cummings, L.L. (Eds.), Research in Organizational Behavior, JAI Press, Greenwich, CT, Vol. 10, pp. 213-255.

Brockner, J. and Greenberg, J., (1990). The Impact of Layoffs on Survivors: An Organizational Justice Perspective, in Carroll, J.S. (Ed), Applied Social Psychology and Organizational Settings, Hillsdale, N.J., Erlbaum, pp. 45-75.

Brockner, J., Grover, S., Reed, T., Dewitt, R. and O'Malley, M. (1987). Survivors' Reactions to Layoffs: We Get by with a Little Help for Our Friends. Administrative Science Quarterly, 32, No. 4, pp. 526-541 
Brockner, J. and Siegel, P. (1996). Understanding the interaction between procedural and distributive justice: the role of trust. in Kramer RM and Tyler T (eds.) Trust in Organisations Thousand Oaks, CA., Sage. pp. 390-413

Brockner, J., Tyler, T.R. and Cooper-Schneider, R., (1992). The Influence of Prior Commitment to an Institution on Reactions to Perceived Unfairness: The Higher They Are, the Harder They Fall. Administrative Science Quarterly, Vol. 37, pp. 241-261.

Brockner, J. and Wiesenfeld, B., (1993). Living on the Edge (of Social and Organizational Psychology): The Effects of Job Layoffs on Those Who Remain, in Murnighan, J.K., Social Psychology in Organizations, Englewood Cliffs, N.J., Prentice Hall, Chapter 6, pp. 119-140.

Cropanzano, R. and Greenberg, J. (1997). Progress in Organizational Justice: Tunnelling Through The Maze in Cooper, C.L. and Robertson, I.T. (Eds.) International Review of Industrial and Organizational Psychology, Volume 12, Wiley, Chichester. Reprinted in Cooper, C.L. and Robertson, I.T. (Eds.) (2001).

Organisational Psychology and Development, Wiley, Chichester, pp. 243-298.

Daly, J.P. and Geyer, P.D., (1994). The role of fairness in implementing large-scale change: employee evaluations of process and outcome in seven facility relocations. Journal of Organizational Behaviour, Vol. 15, pp. 623-638.

Dey, I. (1993). Qualitative Data Analysis. London, Routledge

Folger, R. (1977). Distributive and procedural justice: Combined impact of "voice" and improvement on experienced inequity. Journal of Personality and Social Psychology, Vol. 35, pp. 108-119.

Folger, R. and Cropanzano, R., (1998). Organizational Justice and Human Resource Management, Thousand Oaks, CA, Sage.

Folger, R. and Konovsky, M.A. (1989). Effects of procedural justice, distributive justice, and reactions to pay rise decisions. Academy of Management Journal, Vol. 32, pp. 115-130.

Greenberg, J., (1987). A Taxonomy of Organizational Justice Theories Academy of Management Review Vol. 12, No. 1, pp. 9-22

Greenberg, J. and Folger, R. (1983). Procedural justice, participation, and the fair process effect in groups and organizations in Paulus, P.B. (Ed) Basic group processes Spinger-Verlag, New York pp. 235-256

Guest, D. (1998). The role of the psychological contract in Perkins, J. and Sandringham, S. Trust, Motivation and Commitment, Farringdon: Strategic Remuneration Research Centre pp.7-12.

Haslam, S.A. (2001) Psychology in Organizations: The Social Identity Approach. Sage: London. 
Herriot, P., Hirsh, W. and Reilly, P. (1998) Trust and transition: managing today's employment relationship Chichester, Wiley.

Homans, G.C., (1961). Social Behavior: Its Elementary Forms Harcourt Brace Jovanovich, New York.

Lazarus, R.S. and Folkman, S. (1984). Stress, Appraisal and Coping. New York: Springer Publishing Company

Leventhal, G.S. (1976). Fairness in social relationships in Thibaut, J.W., Spence, J.T. and Carson, R.C. (Eds.), Contemporary topics in social psychology. Morristown, NJ: General Learning Press, pp. 211-239.

Leventhal, G.S. (1980). What should be done with equity theory? In Gergen, K.J., Greenberg, M.S. and Willis, R.H. (Eds.) Social exchanges: advances in theory and research. New York: Plenum, pp. 27-55.

Mabey, C. and Salaman, G. (1995). Strategic Human Resource Management, Oxford, Blackwell.

Mayer, R.C., Davis, J.H. and Schoorman, F.D. (1995) An integrative model of organisational trust. Academy of Management Review Vol 20, pp. 709-734.

Mishra, A.K. (1996) Organizational Responses to Crisis In Kramer R.M. and Tyler T.R. Trust in Organizations, Sage, Thousand Oaks, CA, pp. 261-287.

Möllering, G. (2001). The Nature of Trust: From Georg Simmel to a Theory of Expectation, Interpretation and Suspension. Sociology Vo. 35, pp. 403-420.

Pillai, R., Williams, E.S. and Tan, J.J. (2001) Are the scales tipped in favour of procedural or distributive justice? An investigation of the U.S., India, Germany and Hong Kong (China). The International Journal of Conflict Management Vol. 12, pp. 312-332.

Rousseau, M.T., Stikin, S.B., Burt, S.B. and Carmerer, C. (1998). Not so different after all: a cross-discipline view of trust. Academy of Management Review Vol. 23, pp. 393-404.

Thibaut, J. and Walker, L., (1975). Procedural Justice, Erlbaum, Hillsdale, N J.

Tyler, T. R. (1989). The quality of dispute resolution processes and outcomes: measurement and possibilities. Denver University Law Review. Vol. 66, pp. 419-436.

Tyler, T.R. and Lind, E.A. (1992) A relational model of authority in groups. In Zanna, M.P. Advances in experimental and social psychology volume 25, San Diego, CA: Academic Press, pp. 115-191. 
Table 1: Respondents selecting each emotion as one of those about which they felt most strongly

\begin{tabular}{|c|c|c|c|c|c|c|c|c|c|}
\hline \multirow[t]{2}{*}{ Negative emotions } & \multicolumn{4}{|c|}{$\begin{array}{l}\text { Number of times } \\
\text { selected with }\end{array}$} & \multirow[t]{2}{*}{ Positive emotions } & \multicolumn{4}{|c|}{$\begin{array}{l}\text { Number of times } \\
\text { selected with }\end{array}$} \\
\hline & 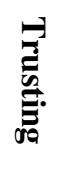 & 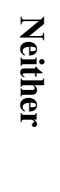 & 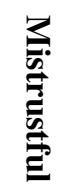 & $\overrightarrow{\stackrel{\theta}{\ddot{D}}}$ & & 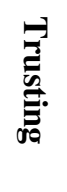 & 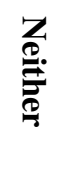 & 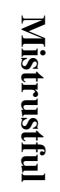 & $\overrightarrow{\underline{0}}$ \\
\hline Frustrated & 1 & 4 & 2 & 7 & Positive & 6 & 3 & 0 & 9 \\
\hline Under pressure & 3 & 2 & 2 & 7 & Determined & 5 & 0 & 2 & 7 \\
\hline Powerless & 2 & 2 & 2 & 6 & Involved & 4 & 2 & 1 & 7 \\
\hline Insecure & 0 & 1 & 1 & 2 & Enthusiastic & 4 & 1 & 0 & 5 \\
\hline Stressed & 0 & 1 & 1 & 2 & Optimistic & 2 & 2 & 0 & 4 \\
\hline Demoralised & 1 & 0 & 1 & 2 & Comfortable & 3 & 0 & 0 & 3 \\
\hline Angry & 0 & 1 & 0 & 1 & Confident & 3 & 0 & 0 & 3 \\
\hline Depressed & 0 & 0 & 1 & 1 & Keen & 3 & 0 & 0 & 3 \\
\hline Overwhelmed & 0 & 0 & 1 & 1 & Hopeful & 2 & 0 & 0 & 2 \\
\hline Worried & 0 & 1 & 0 & 1 & Relieved & 2 & 0 & 0 & 2 \\
\hline Concerned & 1 & 0 & 0 & 1 & In control & 2 & 0 & 0 & 2 \\
\hline On edge & 1 & 0 & 0 & 1 & Cheerful & 1 & 0 & 0 & 1 \\
\hline Confused & 0 & 0 & 0 & 0 & Excited & 1 & 0 & 0 & 1 \\
\hline Disinterested & 0 & 0 & 0 & 0 & Eager & 1 & 0 & 0 & 1 \\
\hline Hopeless & 0 & 0 & 0 & 0 & Relaxed & 0 & 1 & 0 & 1 \\
\hline Indifferent & 0 & 0 & 0 & 0 & Secure & 0 & 1 & 0 & 1 \\
\hline Panicky & 0 & 0 & 0 & 0 & Calm & 0 & 0 & 0 & 0 \\
\hline Resentful & 0 & 0 & 0 & 0 & Expectant & 0 & 0 & 0 & 0 \\
\hline Resigned & 0 & 0 & 0 & 0 & & & & & \\
\hline Vulnerable & 0 & 0 & 0 & 0 & & & & & \\
\hline Total & 9 & 12 & 11 & 32 & & 39 & 10 & 3 & 52 \\
\hline
\end{tabular}

Note: 'Mistrustful' and 'Trusting' were not selected by any respondents as one of their three most strongly felt and are not included in this table. 